\title{
Admissibility assessment of external network based on experimental data equivalence method
}

\author{
Elena Nikolaeva ${ }^{1}$, Alexej Yurganov ${ }^{1, *}$ \\ ${ }^{1}$ Peter the Great Saint-Petersburg Polytechnic University, Institute of Energy and Transport Systems 195251 Polytechnicheskaya \\ 29, Saint-Petersburg, Russian Federation
}

\begin{abstract}
Performing calculations of steady-state regimes and to determine the cutset grid capacity obtaining initial data is quite easy if you know the voltage class of transmission lines and their lengths. That is why such calculations in the RastrWin software environment give a good match to the results in kind. To ensure the results coincidence of transient processes, a significantly larger amount of data on the elements dynamic properties of the system and the tuning of the control systems is needed. Therefore, calculations provide an opportunity to compare the effectiveness of various excitation systems, but quantitative estimates of the limits of sustainability in nature and the model, as well as the configuration of excitation system often do not coincide. In the Russian Federation, a methodology for the equivalence of the external network of power plants based on experimental data has been developed and is successfully applied in practice. As a result, it becomes possible to promptly perform stability forecast calculations by dispatching personnel and to select the setting of the automatic control system for excitation by operational personnel in the circuit directly during commissioning tests at power plants. This paper describes accuracy and efficiency assessment of this methodology.
\end{abstract}

\section{Introduction}

The calculation of aperiodic static stability of any complex power system (PS) is easy to implement and its results are quite accurate. Meanwhile analysis of oscillating stability is more complicated procedure and its results are not often identical with real process behavior because of the dynamic characteristics (which are rarely available) are required for each element of the power system even the last one is not as large as in the fig. 1. It makes us to search another approach to vibrational stability solutions. And this approach is the using of the equivalent circuit, which can be obtained either by manual equivalence or by method of equivalence based on the calculation of steady-state regimes. The study was carried out using the example of a PS, which includes two power stations, replaceable with 2 generators $\mathrm{G} 1$ and $\mathrm{G} 2,4$ load nodes and a ring network

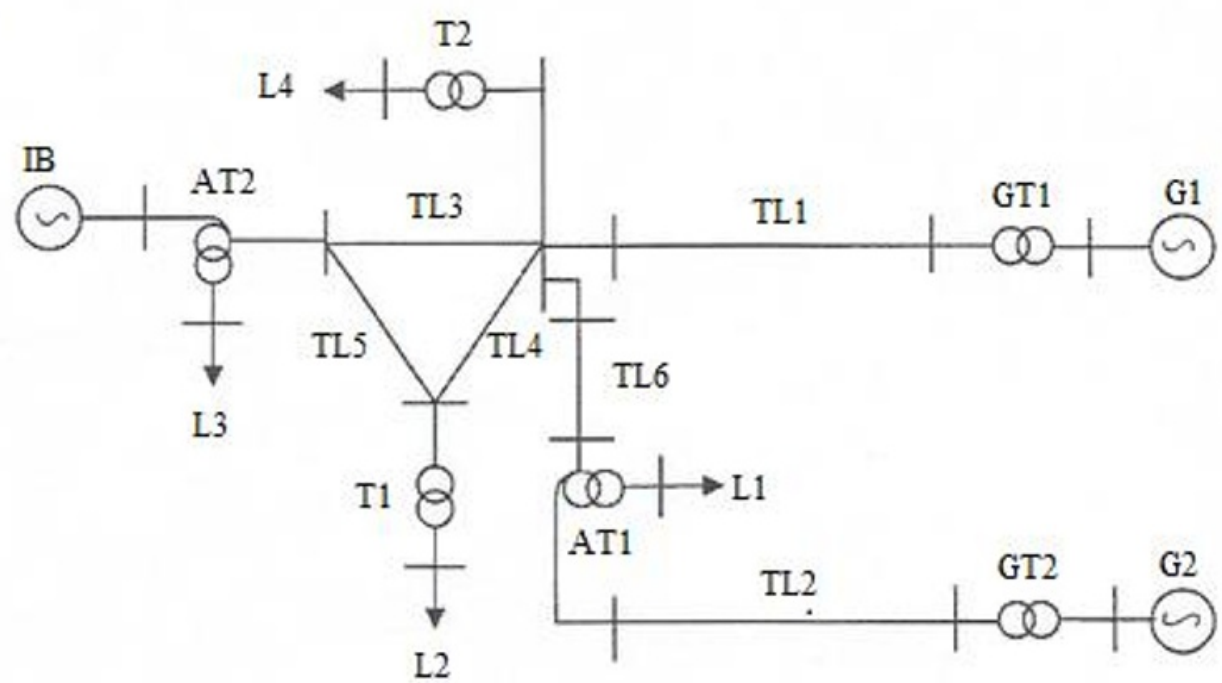

Fig. 1. Scheme of the investigated PS

\footnotetext{
${ }^{*}$ Corresponding author: aayurganov@ mail.ru
} 


\section{Methods}

\subsection{Manual reduction method}

This method is based on manual transformation of initial equivalent circuit of the PS (fig.2), where all elements are inductive reactances, using general reduction rules such as series, parallel and triangle to wye reductions.

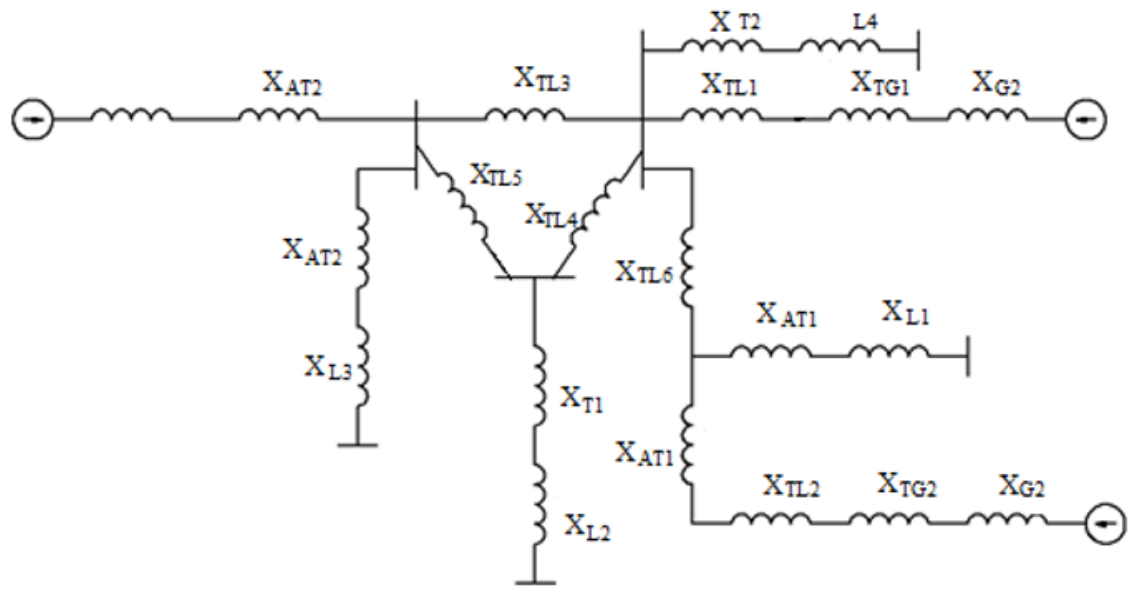

Fig. 2. Equivalent circuit of the investigated PS

It commonly used in approximate short-circuit current calculation which has difference with transient phenomena oscillography recording that is not over 5\%. [1,2] In addition, the reduction is based on the following assumptions:

- Generator rotors are symmetric in magnetic ratio

- The magnetizing current of transformers is not taken into account.

- Capacitive susceptance of transmission lines lower than 220-330 kV is not taken into account.

- Active resistance of power system elements is not taken into account.

- Loads are usually considered as current inductive reactances.

In such a manner the initial scheme (fig. 2) is transformed to the scheme «generator - transmission line infinity power bus» (fig. 3), as a minimum, on the $10^{\text {th }}$ stage of reduction. In case of any changes in the circuit-mode conditions such as load changes, transmission line disconnection, load-balancing of transformers you have to change the original circuit and make all the equivalents again.

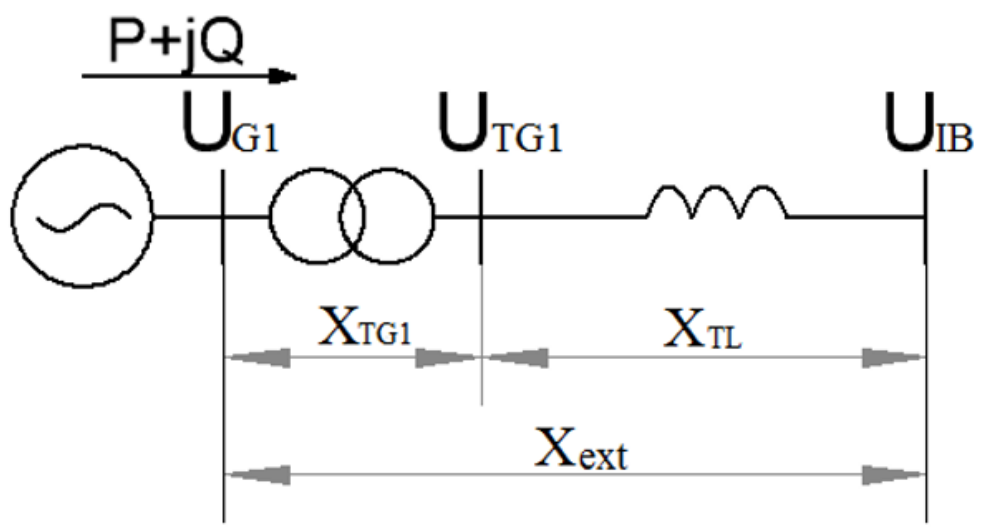

Fig. 3. Equivalent circuit of the electric power transmission, where $U_{I B}$ - phase invariable voltage of initial bus, $U_{G 1}-$ low voltage of the generator transformer, UTG1 - high voltage of the generator transformer, XEXT - complex external equivalent resistance, which replaces the whole PS scheme, $\mathrm{X}_{\mathrm{TL}}$ - equivalent resistance of the PS, which is external to the power station, $\mathrm{X}_{\mathrm{TG} 1}$ - resistance of the generator transformer, $\mathrm{P}$ and $\mathrm{Q}$ - active power and reactive power, which are transmissioned from power station $\mathrm{G}$ to the power grid. 


\subsection{Method of equivalence based on experimental data}

It is based on computational or real experiments to calculate steady-state regimes. They are reduced to the determination of the total values of the active $\mathrm{P} \Sigma$ and reactive $\mathrm{Q} \Sigma$ power and voltage $\mathrm{U}$ on the buses with respect to which equivalence is produced. According to [3], the determination of the value of external resistance from the quadratic equation (1), which includes data obtained for two steady-state regimes with indices 1 and 2.

$$
\begin{aligned}
& \left(I_{1}^{2}-I_{2}^{2}\right) X_{E X T}^{2}-2\left(Q_{1}-Q_{2}\right) X E X T+U_{1}^{2}-U_{2}^{2}=0, \\
& \text { where } I_{i}^{2}=\frac{P_{i}^{2}+Q_{i}^{2}}{U_{i}^{2}}, \mathrm{i}-\text { number of a regime. }
\end{aligned}
$$

The required values of the voltages $\mathrm{Ui}$, active $\mathrm{Pi}$ and reactive Qi powers generated by the station G1, in two regimes (usually $\mathrm{U}_{\mathrm{G} 1}=\mathrm{U}_{\mathrm{G}}$, nom and $\mathrm{U}_{\mathrm{G} 2}=0.95 \mathrm{U}_{\mathrm{G}}$, nom or $\mathrm{U}_{\mathrm{G} 2}=1.05 \mathrm{U}_{\mathrm{G}}$, nom), can be easily obtained by calculating the steadystate regimes in software RastrWin, which is the main software for studies of steady-state regimes among SO UPS, Federal Network Company, design and research institutes in Russia and CIS. The origination of more accurate simplified equivalent PS scheme is achieved due to the following features of RastrWin:

- Calculation of steady-state modes of electrical networks of arbitrary size and complexity, any voltage (from 0.4 to $1150 \mathrm{kV}$ )

- Sufficiently complete and accurate simulation of electrical installations (generators, transmission lines, transformers, linear and bus reactors, etc.)

- Simple modeling of circuit-mode condition changes

- The possibility of more accurate specification of loads through the static response

\section{Results}

The calculation results of the network external resistance for the power station G1 of the studied PS are presented in Table 1. The bases are the nominal values of capacity and voltage of the power station G1.

\begin{tabular}{|c|c|c|c|c|c|c|c|}
\hline \multirow{3}{*}{\multicolumn{2}{|c|}{$\begin{array}{l}\text { Scheme of } \\
\text { calculation схема }\end{array}$}} & \multicolumn{6}{|c|}{ Resistance, p. u. } \\
\hline & & \multicolumn{2}{|c|}{$X_{T G}$} & \multicolumn{2}{|c|}{$X_{T L}$} & \multicolumn{2}{|c|}{$X_{E X T}$} \\
\hline & & $a$ & $b$ & $a$ & $b$ & $a$ & $b$ \\
\hline \multirow{3}{*}{ 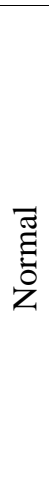 } & $\begin{array}{l}\text { Initial scheme } \\
\text { with regard for } \\
\mathrm{R} \text { and } \mathrm{C} \text { of the } \\
\text { transmission } \\
\text { lines }\end{array}$ & - & 0.03 & - & 0.352 & - & 0.382 \\
\hline & $\begin{array}{l}\text { Scheme, where } \\
\mathrm{R} \text { and } \mathrm{C} \text { of the } \\
\text { transmission } \\
\text { lines are not } \\
\text { taken into } \\
\text { account }\end{array}$ & 0.065 & 0.044 & 0.32 & 0.331 & 0.385 & 0.375 \\
\hline & $\delta \%$ & -9 & -4 & 9 & 6 & -0.8 & 1.8 \\
\hline \multirow{4}{*}{ : } & Transmission & 0.065 & 0.026 & 0.351 & 0.383 & 0.416 & 0.409 \\
\hline & disconnection & \multicolumn{2}{|c|}{$\delta=-9 \%$} & \multicolumn{2}{|c|}{$\delta=8 \%$} & \multicolumn{2}{|c|}{$\delta=-1.7 \%$} \\
\hline & Compensating & 0.065 & 0.03 & 0.316 & 0.349 & 0.381 & 0.379 \\
\hline & $\begin{array}{l}\text { load nodes } \\
\text { disconnections }\end{array}$ & \multicolumn{2}{|c|}{$\delta=-9 \%$} & \multicolumn{2}{|c|}{$\delta=9 \%$} & \multicolumn{2}{|c|}{$\delta=-0.5 \%$} \\
\hline
\end{tabular}

Table 1. Calculation results of the network external resistance

The values of resistances in bold were taken for the true ones, when determining the methods error. The error in calculating the total equivalent external resistance for a generator operating in a complex circuit does not exceed $2 \%$. Errors in calculating the element resistances of a complete equivalent circuit may be greater, but they are usually mutually compensated. The effect of the transmission line or compensating devices in the load nodes disconnections are equally reflected in external resistance increasing in both methods (Table 2). 
Table 2. Effect of circuit-mode condition changes on the amount of the external equivalent resistance obtained by different methods

\begin{tabular}{|l|l|l|l|}
\hline \multirow{2}{*}{$\begin{array}{l}\text { Scheme } \\
\text { changes }\end{array}$} & \multicolumn{2}{|l|}{$\begin{array}{l}\text { Error with respect to normal } \\
\text { scheme }\end{array}$} & $\boldsymbol{\Delta}$ \\
\cline { 2 - 4 } & $\begin{array}{l}\text { Manual } \\
\text { reduction }\end{array}$ & $\begin{array}{l}\text { Experimental } \\
\text { reduction }\end{array}$ & $\%$ \\
\hline $\begin{array}{l}\text { Transmission } \\
\text { line TL5 } \\
\text { disconnection }\end{array}$ & $9.1 \%$ & $8.1 \%$ & 1 \\
\hline $\begin{array}{l}\text { Compensating } \\
\text { devices in the } \\
\text { load nodes } \\
\text { disconnections }\end{array}$ & $1 \%$ & $1 \%$ & 0 \\
\hline
\end{tabular}

The values of external resistances obtained experimentally in all cases take a lower value than the one found by the equivalence "manually". As a result, the first ones determine larger current magnitude, thereby it ensures engineering reserve when we choose switchgear equipment, relay settings, etc. On the contrary, if we take the resistance found "manually" in further calculations, the short-circuit current will be less than it can be in the real circuit, which will lead to known unfavorable situations.

\section{Conclusion}

1. The experimental method for determining the external equivalent resistance is quite accurate, being much less time consuming at the same time.

2. The obtained results allow us to recommend the method of equivalence based on experimental data to apply for the dispatcher's express calculations and for the tuning of the synchronous generator excitation system.

\section{References}

1. N.N. Schedrin Simplificaton of electrical systems in simulation, 160 (1966)

2. A. N. Belyaev, M. A. Lyulina, G. A. Pershikov, V. S. Chudnyi Fundamentals of transient processes in electric power systems: guidelines for course design, 39 (2016)

3. A. A. Jurganov, V. A. Kozhevnikov Regulation of synchronous generators excitation,138 (1996) 